\title{
Perceptions of physician leadership in Botswana
}

\author{
L Sokol-Hessner, ${ }^{1} \mathrm{MD}$; B M Tsima, ${ }^{2} \mathrm{MD} ; \mathrm{C}$ J Dine, ${ }^{3} \mathrm{MD} ;$ B Masheto, ${ }^{4} \mathrm{MD} ; \mathrm{J}$ A Shea, ${ }^{3} \mathrm{PhD} ; \mathrm{J}$ Masunge, ${ }^{4} \mathrm{MD}$; \\ O Nkomazana, ${ }^{2} \mathrm{MB} \mathrm{ChB}, \mathrm{FCOphth}, \mathrm{MSCEH}$
}

\author{
${ }^{1}$ University of Pennsylvania, Internal Medicine Residency Program, Global Health Track, Philadelphia, USA \\ ${ }^{2}$ University of Botswana School of Medicine, Gaborone, Botswana \\ ${ }^{3}$ University of Pennsylvania, Department of Medicine, Philadelphia, USA \\ ${ }^{4}$ Nyangabgwe Referral Hospital, Francistown, Botswana
}

Background. Physician leadership is essential for the strengthening of health systems, especially in underserved settings such as sub-Saharan Africa. To be effective, leaders must be perceived as such by their community. It is unknown how perceptions of physician leadership in Botswana compare with those of the Canadian Medical Education Directives for Specialists (CanMEDS) Physician Competency Framework, which is used to shape the training of Botswana's future physicians.

Objective. To examine if the perceived competencies of physician leadership in Botswana are specifically named in the CanMEDS Framework and thereby inform Botswana's graduate medical education.

Methods. We conducted focus groups discussions with nurses, interns, medical officers and specialists at Princess Marina Hospital and Nyangabgwe Referral Hospital. Key questions focused on describing the qualities of physician leadership. For data analysis we used inductive content coding and comparison with the CanMEDS frameworks.

Results. Forty-eight clinicians participated and 111 unique codes were assigned to 503 comments. Eighty-four per cent of comments corresponded to the CanMEDS 2005 competencies; many were captured within the competencies of the medical expert (13.0\%), communicator (17.8\%), collaborator (15.6\%), scholar (14.9\%) and professional (31.3\%) roles. About 5\% of comments mapped to the draft CanMEDS 2015 update, and $11.5 \%$ were not specifically described in either version of CanMEDS, including charisma and decisiveness.

Conclusion. The CanMEDS frameworks specifically address most of the competencies perceived as important for physician leadership in Botswana. Additional perceptions were identified that may require the attention of existing and aspiring physician leaders and their teachers to ensure they attain and maintain their effectiveness as leaders.

Afr J Health Professions Educ 2015;7(1):26-31. DOI:10.7196/AJHPE.312

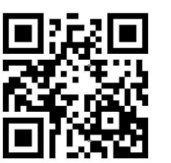

Botswana has significant healthcare challenges; the effects of the 'brain-drain' and HIV in southern Africa have been well described. Effective leadership is required to successfully strengthen Botswana's health system and address these challenges. However, there is a persistent need for more leadership in healthcare, especially in underserved areas. ${ }^{[1,2]}$

Physicians have a unique role in health system improvement, given their significant influence. ${ }^{[3,4]}$ Some have specifically called for physicians to be 'change agents' who drive the strengthening of health systems. ${ }^{[3-6]}$ Fortunately, there is a growing consensus that physicians can be taught leadership skills. ${ }^{[1,7,8]}$ Graduate medical education (GME) is an ideal time and setting to begin teaching leadership, as many physicians first exercise their leadership skills in the clinical training environment. ${ }^{[7,9]}$ In Botswana, the recent establishment of a number of residency programmes highlights the ideal time to investigate physician leadership.

Medical educators aim to train physicians towards a set of competencies. For example, in Botswana the residency programme curricula have been informed by the Canadian Medical Education Directives for Specialists (CanMEDS) Physician Competency Framework, developed by the Royal College of Physicians and Surgeons of Canada in the 1990s, updated in 2005 and currently being updated for 2015. ${ }^{[10,11]}$ Other medical education organisations utilise similar competency frameworks. ${ }^{[5,12,13]}$ While GME traditionally focused on clinical training, these frameworks include additional competencies.

Even though the frameworks are comprehensive, competent physicians are not necessarily effective leaders. The reason may be found in the most widely cited (neocharismatic) leadership theories, including the hypothesis that for leaders to be effective they must be perceived to be leaders by those they lead. ${ }^{[14]}$ Having the competencies of a physician, may not be sufficient to ensure effectiveness as a leader. An important question for Botswana is whether the use of CanMEDS alone will produce not only competent physicians, but also effective physician leaders.

If physician leadership is perceived differently in Botswana from what is explicitly described in the CanMEDS framework, these differences could inform the GME curriculum. To date, the CanMEDS 2015 update has had only limited input from one southern African country (CanMEDS administrative staff (canmeds@royalcollege.ca), question about CanMEDs, 2014 - personal communication).

Alternatively, if perceptions of physician leadership are well described by CanMEDS, it would lend validity to use of the framework to shape physician leadership education.

While CanMEDS 2005 and the draft 2015 update include the concept of leadership, both tend to describe it in nonspecific terms (Appendix 1). Understanding perceptions of physician leadership in Botswana could deepen our understanding of the terms used in the frameworks, such as 'collaborative leadership', 'followership' and 'personal leadership skills'.

To understand perceptions of physician leadership in Botswana, we focused on Botswana's two main teaching hospitals, Princess Marina Hospital (PMH) in Gaborone and Nyangabgwe Referral Hospital (NRH) in Francistown. We concentrated on perceptions of physicians in internal medicine because of their primary roles in the academic hospital environment, and as internal 
medicine was one of the first residency programmes introduced at the University of Botswana. We also included nurses, as they have traditionally held many of the leadership positions in Botswana's health system and work closely with physicians at all levels of training. ${ }^{[15]}$

\section{Methods \\ Study design and participants}

We conducted focus group discussions in March 2010. All participants worked in the medical wards at PMH and NRH and voluntarily took part after being recruited via verbal announcements on the wards by study investigators. Each focus group consisted of one type of medical professional (nurses, interns, medical officers and specialists) at each of the two hospitals for a total of eight groups. Interns have completed medical school and medical officers have completed an internship, while specialists have completed a residency. The ethical committees at the Botswana Ministry of Health, PMH, NRH, and the University of Pennsylvania approved the project.

\section{Procedures and statistical analysis}

We designed the moderator script to elicit participants' perceptions of qualities necessary for physician leadership. The focus group guide from previous work ${ }^{[16]}$ was reviewed by researchers familiar with qualitative research in Botswana. In the lead question participants had to recall a scenario where they either acted as or observed a physician leader and describe the qualities that made the physician a good leader. Discussion was primarily in English - the official language of the hospital environment but participants were encouraged to express themselves in the local language (Setswana), if preferred. We recorded and transcribed each session, and a reviewer from Botswana translated as necessary.

Inductive content coding was used to analyse the data. Two persons (BM, LSH) reviewed transcripts and analysed text content to identify the main themes. An iterative process of revision was used to develop a coding scheme, which was then approved by the entire research team before training a third reviewer (BMT) who was not involved in creating the scheme. Two reviewers (BMT, LSH) then worked independently to recode each transcript, and differences in coding were reconciled collaboratively. Where the reviewers could not reconcile their differences, the coding by the reviewer from Botswana was used for the final analysis. Trustworthiness of the analysis was examined by member checking and comparing the themes to leadership models from previous work. We then compared the focus group comments with the language used in the CanMEDS 2005 Physician Competency Framework and the publicly available information about the upcoming CanMEDS 2015 update. Comments that were not clearly represented in either of the CanMEDS versions were organised into categories informed by a review of the physician leadership literature.

\section{Results}

Fifteen nurses, 12 interns, 12 medical officers, and 9 specialists participated. Nineteen of the participants were from PMH and 29 from NRH. Twentyfive $(52 \%)$ were women. Inductive content coding generated 111 unique codes in our coding scheme; these were assigned to 503 comments. Kappa ranged from 0 to 1.0 , and a median of 0.66 .

Some participants discussed leadership in the contexts of education, administration or research scenarios, but most described physician leaders in terms of their role in healthcare teams. Table 1 shows the number and percentage of comments and the CanMEDS 2005 roles with which
Table 1. Focus group perceptions specified by CanMEDS 2005, $N=422(83.9 \%)^{*}$

Medical expert, $n=55$ (13.0\%)

Is knowledgeable, smart, or competent

Is humble

Has practical skills

Spends time with patients

Examines patients (i.e. 'laying on of hands')

Treats patients holistically

Has good judgement

Acknowledges shortcomings

Is resourceful

Is knowledgeable about patients

Is knowledgeable about traditional medicine

Is hands-on

Applies knowledge in context

Is cautious

Communicator, $n=75$ (17.8\%)

Listens

Is approachable

Communicates

Communicates with colleagues

Communicates with patients

Communicates proactively

Communicates with patients in terms they understand

Communicates with relatives

Justifies his/her reasoning

Respects patient beliefs or opinions

Respects patient confidentiality

Is empathetic or reassuring

Avoids unnecessary barriers between themselves and patients

Addresses patient concerns

Is transparent

Documents properly

\section{Collaborator, $n=66(15.6 \%)$}

Is not a dictator and does not abuse power

Asks for and considers input from colleagues, even subordinates

Works well in teams

Is knowledgeable about the team

Relates well with others

Addresses and solves problems

Does not humiliate

Has the interest of the team in mind or promotes team spirit

Is proactive or takes initiative

Is willing to learn from colleagues

Delegates 
Table 1. (continued) Focus group perceptions specified by CanMEDS 2005, $N=422(83.9 \%)^{*}$

\section{Collaborator (continued)}

Searches for underlying problems

Is able to take direction from others

Manager, $n=21(5.0 \%)$

Is organised

Is knowledgeable about the work environment or system

Is disciplined or focused

Is able to navigate the system they work in

Health advocate, $n=10(2.4 \%)$

Advocates for patients

Is knowledgeable about the community

Is knowledgeable about the culture

Collaborates with communities

Scholar, $n=63$ (14.9\%)

Gives constructive feedback

Guides others

Is willing to learn

Teaches

Accepts criticism

Acknowledges achievements and appreciates others

Does research

Keeps up to date

Is academic

Encourages

Practises evidence-based medicine

Gives feedback

Is a mentor

Is willing to change

Seeks constant improvement

Is reflective or evaluative

Gives advice

Professional, $n=132$ (31.3\%)

Is professional

Is fair or impartial

Respects and values others

Is a model or leads by example (i.e. exemplary)

Is committed or dedicated

Is hard working

Is honest or straightforward

Takes responsibility

Is accessible

Is thorough

Is patient

Is trustworthy
Table 1. (continued) Focus group perceptions specified by CanMEDS 2005, $N=422(83.9 \%)$

\begin{tabular}{|c|c|}
\hline Professional (continued) & \\
\hline Has good morals or is a good person & 4 \\
\hline Has botho & 4 \\
\hline Is reliable & 3 \\
\hline Is accountable & 3 \\
\hline Is non-judgemental & 3 \\
\hline Is compassionate & 3 \\
\hline Is able to control their emotions or manage their personality & 3 \\
\hline Acknowledges mistakes & 2 \\
\hline Is non-racial & 2 \\
\hline Balances confidence and humility & 2 \\
\hline Is presentable & 1 \\
\hline Meets targets & 1 \\
\hline Is respected by the community & 1 \\
\hline Is determined & 1 \\
\hline Is forgiving & 1 \\
\hline Is flexible & 1 \\
\hline
\end{tabular}

they matched best. Within that group of comments, most focused on the competencies of the medical expert (13.0\%), communicator (17.8\%), collaborator $(15.6 \%)$, scholar $(14.9 \%)$ and professional $(31.3 \%)$ roles and very few on the health advocate or manager role. An additional $4.6 \%$ of all comments were best matched to the draft 2015 update (Table 2), and 11.5\% of comments did not fit easily into either version of CanMEDS (Table 3). Below we expand upon themes.

\section{Perceptions of physician leadership and CanMEDS 2005 Medical expert}

Being a medical expert was very important to participants - they commented on the importance of being knowledgeable, smart and competent 21 times, the single most common comment overall. Practising comprehensive patient care, including 'taking time with the patient', being aware of alternative medicine and applying knowledge in the socioeconomic context were also seen as important aspects of leadership.

\section{Communicator}

Communication had many aspects: 'You should have good communication skills, to the patients, to your subordinates ... to ... your superiors'. Listening well and approachability were key: 'There should be no fear of being reprimanded'. As one participant said, '[proactive communication] should start on admission, straight away until discharge'.

\section{Collaborator}

Respect, support and encouragement were fundamental to teamwork: '... help us feel that ... you can see how we are struggling to make things better ... show appreciation to [the team]'. Not being a 'dictator' was mentioned many times: 'Often people ... turn leadership into a dictatorship, thinking that they will succeed, and that's very dangerous'. 
Table 2. Additional focus group perceptions of physician leadership specified in the draft CanMEDS 2015 update. New CanMEDS 2015 language not present in the 2005 version is delineated in italics, $N=23(4.6 \%)^{*}$

\section{Medical expert}

$7(30.4 \%)$

Promotes accountability or holds others accountable

Enabling competencies: 4.1 Establish the roles of the patient and

all team members for follow-up on investigations,

response to treatment, and consultations, and ensure that the

agreed follow-up occurs

Leader (previously manager)

$14(60.9 \%)$

Has a vision or plan

Sets expectations or targets

Role description: At a system level, physicians contribute to the development and delivery of continuously improving

healthcare and engage others to work with them toward this vision

\section{Scholar}

Is innovative or creative

Key concepts: Clinical innovation

There were no additional comments mapping to the communicator, collaborator, health advocate or professional roles.

${ }^{*}$ Number of comments, denominator for $\%$ is all comments.

Participants felt strongly that leaders should search for underlying problems and their solutions, as one participant explained: 'When there is a problem, a good leader should be bold enough to ... confront it'. The ability to delegate was essential: 'A good leader ... has to be able to use the mind of others ... he has to know how to utilize those under him' Asking for help was perceived as a strength: '[a leader] shouldn't be ... shy to ask ... for a second opinion if he feels he's failing ... they should accept opinions from their subordinates'

\section{Manager}

There were few comments about being a manager. Several participants said: 'It's very essential, as a ... good leader, to manage your time'. Understanding the work environment and healthcare system was of strategic importance: 'Research about everything that is ... happening, like in the unit that you are'. Another said: 'Even when the system is very difficult, you have to find your way ... around the system'

\section{Health advocate}

There were also very few comments about this role. One participant said 'You have to have your patient's best interest, everything will come from that'. Another explained: 'If you see a need for that patient to be done ... you have to convince whoever is against that idea that it should be done for the patient'.

\section{Scholar}

The importance of seeking constant self-improvement was described in several ways, especially with regard to being up-to-date and evidence based: 'I think also you have to be academic. They have to know what the latest journals are saying ... because as a leader, you should be able to make such decisions when your juniors come [to you with questions].' Other participants emphasised teaching and giving feedback: 'You should be able
Table 3. Additional focus group perceptions of physician leadership not specified by CanMEDS 2005 or the 2015 draft, $N=58(11.5 \%)^{*}$

\begin{tabular}{ll}
\hline Charismatic & $26(44.8 \%)$ \\
Is inspiring or motivating & 9 \\
Unifies & 6 \\
Is passionate about their work & 4 \\
Is friendly & 4 \\
Is likeable & 2 \\
Has a good attitude & 1 \\
Decisive & $29(50.0 \%)$ \\
Is confident or assertive & 13 \\
Is decisive or takes a stand & 8 \\
Is firm & 8 \\
Miscellaneous & $3(5.2 \%)$ \\
Is experienced & 2 \\
Distinguishes themselves & 1 \\
${ }^{*}$ Number of comments, denominator for \% is all comments. &
\end{tabular}

to be a good teacher ... because [your students] are going to end up where you are'. 'A good leader is one who comes to you and says, "I think you need to improve on these areas"' Being a mentor, giving advice and guiding others were also important: 'You ... have a group of young ... newly qualified doctors who have no clue what the world of medicine is like ... you need to mentor it'. Another participant said: 'For me a leader is the one who guides, or who shows where is the path, the route'

\section{Professional}

Of all the CanMEDS roles, the professional was mentioned most $(26 \%$ of all comments), and participants were most impassioned about this role: 'In medicine you should expect somebody to assume some level of professionalism ... we deal with human beings, you miss a boat, somebody loses their life. Many noted that leaders always conduct themselves as such, even when they are not in a formal leadership role. Other aspects of being a professional included commitment, work ethic, honesty, fairness, impartiality, a sense of morals and accountability. Participants also mentioned leaders needing to have botho. One of Botswana's former presidents said: 'Botho is a state of being humane, courteous and highly disciplined ... the value attached to life is central to the principle of botho. ${ }^{\text {[17] }}$ A focus group participant said: 'Botho [means] you know how to treat every human being right, and you know to respect everything.

Being a role model was mentioned many times: 'A leader should live an exemplary life ... because if you just act professionally in front of the people you are leading, and outside that, you act like ... somebody I don't know, I want to take you as a pretending leader. The importance of leading by showing was described several times: 'Before people follow you, you must be a model ... if I expect my houseman to work up until 5:30, I must also be willing to work ... . I expect my houseman to do a lumbar puncture, I should be able to do a lumbar puncture.' Leaders also needed to have humility and balance: 'You should be cautious of what conclusions you reach'; another said: 'That's the ... leadership skill, to know how to react, you need to know when to be flexible, but you need to know when to put your foot down as well'. 


\section{Perceptions of physician leadership and the draft CanMEDS 2015 update}

\section{Medical expert}

The updated language in one of the enabling competencies refers to the concept of accountability (Table 2). A participant said: 'Part of what leaders do also is help other people be accountable, not just themselves'.

\section{Leader (formerly manager)}

The authors of the Expert Working Group for the manager role in the 2005 framework decided to change the name of the role to leader for the 2015 update and for the first time included the concept of vision. '... a good leader is one who would have ... short term and long term goals.' An example of how to set targets to engage one's team was: 'Ok, I can see that this is the way that things are being done, but my dream and my goal is for us to develop in this field and ultimately move to ... this level. So how can we reach that level?' Another said, 'I also think a good leader should have a vision ... so that he's able to guide his team where ... they are going in the right direction'

\section{Scholar}

The key concepts for this role in the 2015 update include innovation, and one of the participants said: 'A good leader should also be innovative. Bringing in new ideas'.

\section{Additional perceptions of physician leadership}

There were a number of comments on perceived qualities of physician leadership that were not clearly identified in CanMEDS 2005 or the draft 2015 update.

\section{Charismatic}

The ability to be a positive figure was identified many times: 'For you to inspire other people, you should show passion to your work. You shouldn't be called to come and do your work. You should come and look for work.' Physician leaders 'get people to do stuff, but ... they don't fight with them ... they just make things happen'. Another participant offered a key insight: '[the leader] may have a very brilliant idea, but if she comes and says ... it's her idea [then we won't do it] ... but if she comes and puts it on the table, we discuss, it becomes our idea ... then we will do it all'.

\section{Decisive}

There were $>30$ comments about having a 'strong personality, somebody who ... is ... comfortable with [themselves]'. Participants felt this was necessary for teams to have confidence in their leaders.

\section{Discussion}

Our study is the first to describe the overlap between the perceived competencies of physician leaders and an existing GME competency framework used in Botswana and much of southern Africa. Eighty-four per cent of the comments by focus group participants were consistent with the CanMEDS 2005 framework, while 5\% were consistent with language found in the draft 2015 update. These focused on the concepts of vision - which has been noted in multiple other physician leadership studies $^{[4,7-9]}$ - and promoting accountability. The results suggest that training physicians according to the CanMEDS framework, especially after the 2015 update, will cover most of the perceived competencies for effective physician leadership. Although more comments were consistent with the professional than any other role, the single most common comment was about being a knowledgeable, smart, competent medical expert. The centrality of medical expertise for physician leaders has been previously noted ${ }^{[3,16]}$ and was validated by our participants, who primarily referred to physician leadership in the context of clinical teams in the hospital.

Beyond the perceptions that matched well with the two versions of CanMEDS, we found that $>11 \%$ of comments were about charisma and decisiveness. Neocharismatic leadership theories are the most widely cited outside of medicine; ${ }^{[14]}$ therefore it is not surprising that our focus groups perceived charisma to be important. To date, the concept of decisiveness has not been a prominent part of the leadership literature and may be worth investigating further. Nevertheless, the perceptions not captured in the CanMEDS frameworks may be part of how healthcare providers in Botswana would consider the terms 'collaborative leadership', 'followership' and 'personal leadership skills', which are used by the authors of the CanMEDS 2015 update.

Notably absent from the comments were the roles of health advocate and manager. Although it is not clear why these roles were emphasised less often, it is not a novel occurrence. An evaluation of the CanMEDS framework in Canada found that many programmes had not used the health advocate or manager roles in their curricula as often as the other roles. ${ }^{[10]}$ Based on other physician leadership work, especially focusing on administrative and executive leadership positions, we know that these roles are often very important and therefore may require additional attention when designing curricula. ${ }^{[4,9]}$ Future work may explore why participants did not mention these skills more frequently.

Our study had several limitations. We only investigated one setting with a limited number of providers, which may limit the generalisability of the results to other contexts. This is mitigated somewhat by the similarities between the leadership competencies identified and those described in previous work. ${ }^{[7,16]}$ Secondly, although clinicians in Botswana are from many different cultures, our study was not designed to determine how these cultures may view physician leadership. Awareness of cultural differences may be an important part of developing effective physician leadership assessment tools and training programmes ${ }^{[4]}$ Thirdly, participants in focus groups may have been unwilling to discuss certain characteristics in the presence of others. Attempts were made to minimise this effect by ensuring that groups were composed only of colleagues of the same clinical training, emphasising anonymity of comments, and conducting groups in a non-judgemental way.

\section{Conclusion}

Our research on perceptions of physician leadership demonstrates good congruence with the GME framework used in Botswana and reveals insights that can inform aspiring and established leaders and their teachers. Some have been sceptical about whether the competencies of physician leadership can be taught ${ }^{[8]}$ but as we have shown, most of what nurses, interns, medical officers and specialists in Botswana perceive as important for physician leadership are already part of GME curricula. Future work could include the use of innovative educational methods, such as structured individualised learning plans to teach and reinforce leadership competencies. ${ }^{[4,7,9,18]}$ In addition, the development of physician leadership assessment tools could strength physician leadership training. ${ }^{[9,18]}$ Competencies that are measured will be more highly valued, both by educators and students. 


\section{References}

1. Levey S, Hill J, Greene B. Leadership in health care and the leadership literature. J Ambulatory Care Manage 2002;25(2):68-74.

The resource leadership. The key to improved results in health. Hum Resour Health 2008:6(1):10. Reinertsen JL. Physicians as leaders in the improvement of health care systems. Ann Intern Med 1998;128(10):833-838 4. Farrell JP, Robbins MM. Transformational leadership. Leadership competencies for physicians. Health Forum I 1993;36(4):39-42

5. Scottish Deans' Medical Curriculum Group. The Scottish Doctor. 2007. http://www.scottishdoctor.org/ (accessed 29 December 2014).

6. Frenk J, Chen L, Bhutta ZA, et al. Health professionals for a new century: Transforming education to strengthen health systems in an interdependent world. Lancet 2010;376(9756):1923-1958. [http://dx.doi.org/10.1016/S0140 6736(10)61854-5]

7. Kuo AK, Thyne SM, Chen HC, West DC, Kamei RK. An innovative residency program designed to develop leaders to improve the health of children. Acad Med 2010;85(10):1603-1608. [http://dx.doi.org/10.1097 ACM.0b013e3181eb60f6]

8. Taylor CA, Taylor JC, Stoller JK. Exploring leadership competencies in established and aspiring physician leaders An interview-based study. J Gen Intern Med 2008;23(6):748-754. [http://dx.doi.org/10.1007/s1 1606-008-0565-5] 9. Crites GE, Ebert JR, Schuster RJ Shuster RJ. Beyond the dual degree: Development of a five-year program in leadership for medical undergraduates. Acad Med J Assoc Am Med Coll 2008;83(1):52-58.
10. Frank J ed The CanMEDS 2005 Physician Competency Framework Better Standards. Better Physicians. Better Care. Ottowa: The Royal College of Physicians and Surgeons of Canada, 2005:9-24.

11. Frank J, Snell L. Draft CanMEDS 2015 Physician Competency Framework - Series I. Ottawa: The Royal College of Physicians and Surgeons of Canada, 2014. http://www.royalcollege.ca/portal/page/portal/rc/common/ documents/canmeds/framework/framework_series_1_e.pdf (accessed 29 December 2014).

12. ACGME. Common program requirements: General competencies. 2007. http://www.acgme.org/outcome (accessed 29 December 2014).

13. General Medical Council. Tomorrow's doctors - outcomes and standards for undergraduate medica education. 2009. http://www.gmc-uk.org/TomorrowsDoctors_2009.pdf_39260971.pdf (accessed 29 December 2014).

14. Dinh JE, Lord RG, Gardner WL, Meuser JD, Liden RC, Hu J. Leadership theory and research in the new millennium: Current theoretical trends and changing perspectives. Leadersh Q 2014;25(1):36-62.

15. Dube A, Jooste $\mathrm{K}$. The leadership characteristics of the preceptor in selected clinical practice settings in Botswana. Curationis 2006;29(3):24-40.

16. Dine C, Kahn J, Abella B, Asch D, Shea J. Key elements of clinical physician leadership at an academic medical center. J Grad Med Educ 2011;3(1):31-36. [http://dx.doi.org/10.4300/JGME-D-10-00017.1]

17. Mogae F. His Excellency Mr Festus Gontebanye Mogae, President of the Republic of Botswana, Independence Day message to the nation. 2003. http://www.botswanaembassy.org/092903_1.html (accessed 29 December 2014).

18. Epstein RM, Hundert EM. Defining and assessing professional competence. JAMA 2002;287(2):226-235.

\section{Appendix 1. Use of the word 'lead' in the context of leadership, in the CanMEDS 2005 framework and draft 2015 update}

\section{CanMEDS 2005}

Collaborator - Enabling Competencies - 1.10. Where appropriate, demonstrate leadership in a healthcare team

Manager - Enabling Competencies - 4. Serve in administration and leadership roles, as appropriate. 4.2. Lead or implement a change in healthcare

\section{Draft CanMEDS 2015}

Rename Manager Role to Leader

Definition: 'As leaders, physicians develop, in collaboration with other healthcare leaders, a vision of a high-quality healthcare system and take responsibility for effecting change to move the system toward the achievement of that vision'

Major content changes include: 'Although diverse opinions were expressed, common ground was found with regard to the need for physicians' personal responsibility, active engagement, and contribution (as ways of conceptualizing leadership)'

Key concepts include: 'collaborative leadership', 'followership', 'leading change', and 'personal leadership skills'

Key competencies include

3. Demonstrate leadership in professional practice

3.1 Develop their leadership skills

3.2 Facilitate change in healthcare to enhance services or outcomes

3.3 Design and organise elements of healthcare delivery 